\title{
FLOOD VULNERABILITY REDUCTION, USING A PARTIAL PARTICIPATORY GIS APPROACH. A STUDY CASE IN BAJA CALIFORNIA SUR, MEXICO.
}

\author{
G. M. Cruz-Bello ${ }^{1}$, M. Alfie-Cohen ${ }^{1}$, N.A. Morales-Zaragoza ${ }^{2}$, A. H. Larralde-Corona ${ }^{1}$, J. Reyes Perez ${ }^{1, *}$ \\ ${ }^{1}$ UAM Cuajimalpa, Social Sciences Department, 05300 CDMX, Mexico - (malfie, gcruz, alarralde)@ correo.cua.uam.mx \\ ${ }^{2}$ UAM Cuajimalpa, Design Theory and Processes Department, 05300 CDMX, Mexico - nmorales@ correo.cua.uam.mx
}

KEY WORDS: Participatory cartography, floods, cyclones, vulnerability reduction

\begin{abstract}
:
A partial participatory GIS approach was implemented in a community in La Paz, Baja California Sur, Mexico to reduce vulnerability of floods caused by cyclones. A workshop was held to locate areas susceptible to floods, and understand measures already taken by the community as well as actions proposed towards vulnerability reduction. We used printed high-resolution satellite images and generative tools to gather data of workshops attendees. Then all information was transferred into a GIS. In addition, we conducted a survey to collect socioeconomic and adaptation data on 490 households (each one identified and spatially located). We analyzed through "chi square" and "gamma tests" the relationship between survey data and houses affected by floods. The map generated was reviewed by risk management experts and used as an input for map validation/refinement from the workshop. The final map was returned to the community and used as an instrument for communication, negotiation, risk management and vulnerability reduction, making spatially explicit areas affected by floods and proposed measures to reduce vulnerability. Despite not finding a statistical (corelation) between the participants education and socio-economic levels or preparedness for risk and the affectations (impacts) by floods. The majority of people showed to be used to local knowledge preventive measures in their household under a cyclone alert and answered to feel prepared to a cyclone arrival. This cyclone awareness could be explained since in this community $40 \%$ of the people had at least 12 years of education. Which is relatively high for a developing country as Mexico where the average of years of study is 9.1. Besides $87 \%$ of the people get a medium to high value in a socioeconomic index created in this study.
\end{abstract}

\section{INTRODUCTION}

Participatory Geographic Information Systems (PGIS) have been mainly used in natural resource management, ecosystem services and environmental planning (Brown, 2012; Cadag and Gaillard, 2012; Brown and Fagerholm, 2015; Zolkafli, et al., 2017). In addition, they have been applied in disaster and risk management (Rom, et al., 2011; Weijiang, 2014; Canevari-Luzardo et al., 2017). In this last context two theoretical categories give support the PGIS approach. Both highlight the importance of this methodology so societies be less vulnerable and adapt more quickly to disasters.

The first theoretical support is risk management, which comprises identification, evaluation and setting up priorities. According to Lavell (2004), risk evaluation is obtained by relating hazard and vulnerability. Understanding risk as a consequence of a multiplicity of factors, including social, political, economic or technological. Therefore, risks must be analyzed from a broad perspective, in which the impact of natural forces on the communities will be privileged (Hewitt, 1983).

Wilches-Chaux (1998) conceived a disaster as a geophysical hazard, such as a hurricane, that has an impact on a territory characterized by a vulnerable social structure. Disasters happen all over the world, however loss of lives is greater in developing countries, because of their high vulnerability driven by their historical development where economic, social, political and cultural conditions are inadequate (UNDP, 2004). In this context, PGIS becomes relevant to risk management helping to unravel community characteristics, strategies and instruments to face risk. Risk management involves reducing vulnerability and mitigating threats, considering collective decisions about admissible risk levels in a given period, and proposing changes to avoid damage to vulnerable communities (Lavell, 2004).

This model consists on gathering information that allows risk calculation, provision of financial and social resources to restore adequate living conditions, establishing communication among several actors to assess progressive changes of risk and social insurance instruments against probable damage.

The second theoretical category supporting the participatory GIS methodology in the context of disaster and risk management has to do with the concept of vulnerability reduction through governance. According to Delgadillo (1996) population vulnerability is affected by inadequate structures; settlements located in areas prone to physical hazards; low income levels; national economic weakness; deficient levels of social organization; passive ideologies regarding relationship humanenvironment; poor environmental education and high population mortality rates. Vulnerability is always referred to some kind of hazard, such as droughts, earthquakes, floods, diseases, or anthropogenic threats such as pollution, industrial or transportation accidents. For Wisner, et.al (2004) talking about vulnerability implies referring to the characteristics of a person or group and their situation, as well as their capacity to anticipate, face, resist and recover from the impact of a hazard event. In Latin America, assistance in case of a disaster has been carried out from a centralist position, where the government decides how and who will receive the aid. Vulnerability reduction through governance is a new path that involves horizontal relationships 
among different social actors to define prevention, restoration and compensation measures, search for early warnings, clear and transparent information and participation in decision-making by governments and the affected communities. It is based on intersectoral collaboration, as a tool to reconnect citizens with the construction of a common purpose and improve decision-making processes (Alfie, 2011 and 2015).

Both, risk management and vulnerability reduction through governance refer to a new approach of dealing with disasters where participatory GIS can have a primordial position allowing the implementation of a new environmental and territorial order. PGIS helps to provide to the community with an instrument for communication, negotiation, risk management and vulnerability reduction through governance, making spatially explicit areas affected by floods, shelters, evacuation routes, and proposed measures to reduce vulnerability based on the joint deliberation of multiple stakeholders.

In this context, we implemented a partial participatory GIS approach in a community in Baja California Sur, Mexico to reduce vulnerability to floods caused by cyclones. A workshop was held to locate areas susceptible to floods, measures already taken, and actions proposed towards vulnerability reduction. We used printed high-resolution satellite images and generative tools to gather data of workshops attendees. The main objective was to provide the community with a spatially explicit instrument for communication and negotiation that help them in the risk management and vulnerability reduction activities. We carried on a survey in the community to gather socioeconomic and general information as well as disaster preparedness degree. These variables were statically compared with flood affectation levels (no affectations, sporadic affectations and repeatedly affectations). No relations were found between general and socioeconomic data or disaster preparedness with the household's affectation levels. However, we found a high level of awareness to flood risk and preparedness to face it, may be due to the relative high average of years of study for a developing country such as Mexico.

\section{METHODOLOGY}

\subsection{Study case}

La Paz is a coastal city located in the northwest of Mexico, and is the capital of the Baja California Sur state. The study case, Chametla, is one of the suburbs of $\mathrm{La} \mathrm{Paz}$, and represents a typical case of peripheral urbanization of the Mexican cities with a fragmented urban grow a long a main road with rural areas in the interstices (Figure 1). Because of this, one can think their inhabitants are more vulnerable to natural hazards as describe in several studies (Allen, 2003; Aragón-Durand, 2007; Hernández and Vieyra, 2010), since the high poverty levels in these spaces and to the irregularity in the land use tenure that make it difficult to improve the urbanization conditions. In addition, there is a disorder in their incorporation to the urban development, sometimes set in non-suitable land due to environmental or risk reasons. As a peri-urban settlement Chametla is a relatively new community developed between 1990 and 2000 as an expansion of La Paz to the west, along the trans-peninsular road that takes to the La Paz International Airport. It is located in the coast lowlands (altitude of $4 \mathrm{~m}$ ). It has 2,178 habitants living in 696 homes (INEGI, 2010). According to the Mexican National Centre on Disaster Prevention (CENAPRED, 2012) Chametla is one of the neighborhoods with high flood risk because of the presence of streams. In fact, at least every two years a hydro meteorological phenomenon affects the area (Martínez-Gutiérrez and Larry Maye, 2004), being the most recent hurricane Newton in 2016 and tropical storm Lidia in 2017.

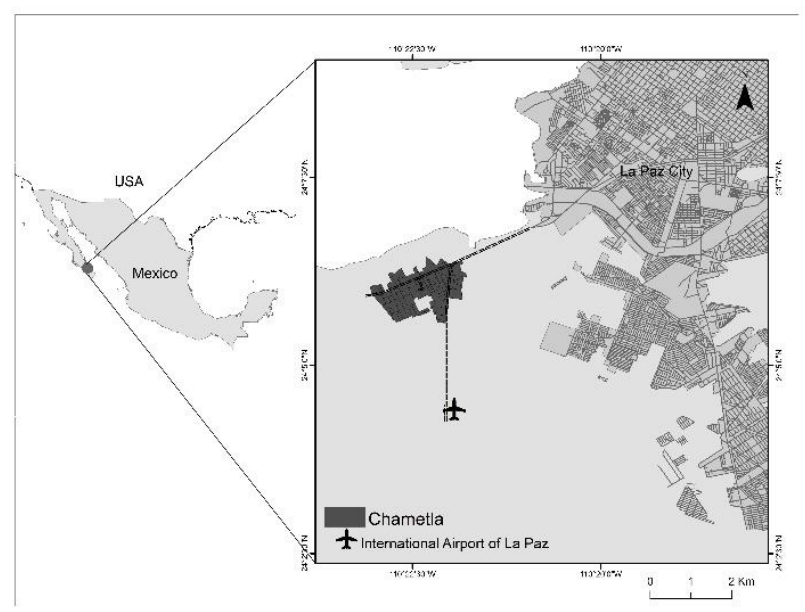

Figure 1. Study case. Chametla, BCS, Mexico.

\subsection{Mapping exercise}

Despite common barriers of good mapping processes capable of engaging relevant stakeholders in the collection and use of information, we decided to use a partial PGIS approach, which Canevari-Luzardo et al. (2017) describe as a highly multidisciplinary mapping technique that uses GI Technologies to validate spatial knowledge and integrates participatory principles which include a commitment to undertake researchinformed actions.

We decided to use a participatory community mapping approach because it addresses the contextual nature of vulnerability considering local knowledge, we were especially interested in this technique since it values the mapping process as much as the products achieved from the activity, and specially challenges academic research through the construction of inclusionary approaches to knowledge co-production.

The methodology used in this research integrates a set of generative tools inspired by Sanders et al., (2010), who proposed an organized system where the participatory action is closely linked with the method or technique (making, telling or enacting) and purpose of the inquiry. This generative toolkit (Sanders and Stappers, 2012) consisted on a set of projective materials typically ambiguously in structure- such as printed images and text (of familiar local places), color dot labels, markers, blank notes and cards, translucent acetate and tape.

These materials were carefully combined with punctual exercises, through the implementation of the whole mapping activity in order to lead the group to engage in a flexible and creative attitude, while the tasks were carried out, these allowed verbal discussions and short presentation while the final map artefact was constructed collectively. Another key feature of this generative approach was a field notebook specially design for the participants to take away after the workshop to continue with the collection of information and to expand the network of participants to other members of the community interested in collaborating.

The use of participatory approaches for knowledge co-production has been a general approach for community mapping and it is considered a good way to facilitate information gathering and the framing of bottom-up strategies in a local mapping context (Williamson, 2011). There are plenty of examples of 
participatory approaches from environmental and social issues, designed to be easily understood (e.g. The Green Map System (2007) based in N.Y.; Parish Maps by Common Ground Project, (2008) and Iconoclasistas in Latin America, (Ares, 2016)). Unfortunately, the integration of Geographic Information System Technologies has potential cartographic limitations when representing cultural and traditional knowledge because of the community limited cartographic literacy and a lack of technical skills, which compromises the results accuracy. Consequently, we decide to use high-resolution printed satellite images to collect the workshop participant's information. After the workshop, one GIS technician was in charge of digitize all the information produced and complemented it with the comments of disaster protection experts.

\section{Workshop participants}

The inclusion of the participants was made through an open invitation to all inhabitants of Chametla through announcements displayed in the windows of convenience stores in the community and by direct invitation to some households by students from one of the state universities, who give local support for this study.

\section{Workshop implementation}

The partial participatory GIS approach developed for the study consisted of one session with local participants. The workshop was held on November 2017 in a local meeting room with neighbors of Chametla. After a brief introduction where the purpose of the activity was stated, participants were asked to connect the images of familiar places of reference with the printed base map (satellite view of the locality) provided, and asked to delimit the areas they knew the best to build a confidence map (Luscombe and Reyes, 2004; Oštir, et al., 2007; MartínezVerduzco et al., 2012). Then each participant was individually asked to identify their house and the areas of mayor risk of flood in the community, then they thought about risk management actions commonly held by the community and identify the most vulnerable areas, as a final task they came up with possible solutions and a strategy to contact local authorities in case of emergencies (Figure. 2). After that, participants presented their results in a plenary session, and had the opportunity to refine/correct the information they put in the map. In the development of this activity one participant mentioned an area out of the limits of the base map that was producing at environment risk that was provided so we had to improvise to project the area in the wall and that was a support to end the plenary session. After that, each participant took a notebook. General instructions were given to fill it and return.

The resulting map was given to risk management experts for their comments, these comments were the integrated in the final map handed back to workshop participants.

To generate the final map, the map produced by the community was digitized and integrated into a GIS environment using ArcGis (ESRIC).

\subsection{Household Survey}

A survey was applied to 490 households in the community. The survey was divided in three sections: 1) General information (age, sex, educative level). 2) Socioeconomic data (house construction materials, number of rooms, amount people are willing to pay for rent, house services, number of person contributing to the income, disability people living in the household), and 3) Disaster preparedness (vulnerability reduction activities, communication with government, aids received from the government, measures taken to prevent disasters, warning mechanisms and modification to their houses). Relationship between houses with three flood affectation levels as identified in the workshop: 1) no affected, 2) sporadically affected and 3) repeatedly affected and results from the survey were statically tested through Gamma and Chi square tests, for ordinal and nominal variables respectively.

Relationships was assessed for individual variables (study level) or questions such as: If there is a hurricane warning do you use some kind of measurements to prevent affectation in your house?; Had you make modifications to your house to reduce flood impacts?; After and hurricane do you ask for help to the local government?, and Do you feel prepared for storm or hurricane? Additionally we created an integrated socioeconomic index as a proxy of wellbeing. We added all positive answers to the questions in your household you have: sink, washing machine, gas stove, solar heater, conditioner air, TV, Flat screen TV, Cable TV, internet, desktop computer, laptop computer, microwave oven, refrigerator, electric iron. We used and equal interval classification approach to group the number of answers in three groups: $1-5,6-10$ and $7-15$ as a low, medium and high socioeconomic index.

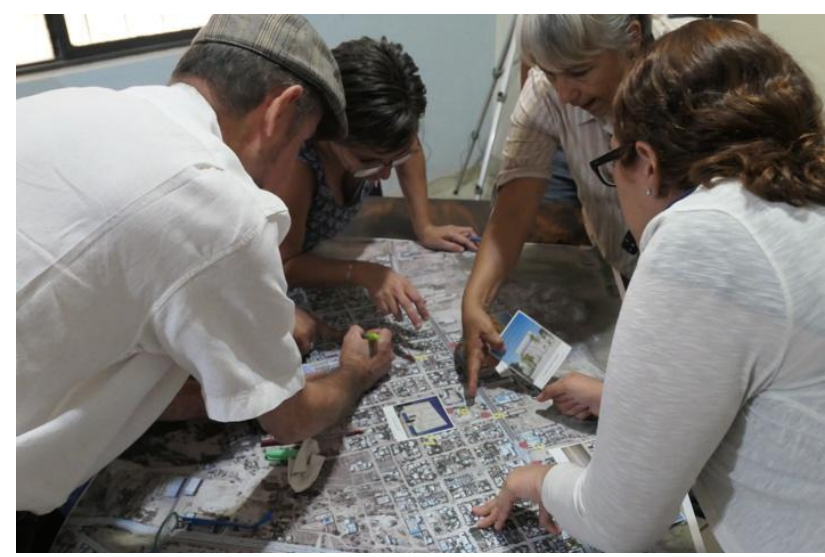

Figure 2. Participants using images from the toolkit to locate familiar places

\section{RESULTS}

\section{Mapping exercise}

Despite an ample invitation to the workshop, there was an assistance of only six people to the workshop, which is considered as sufficient by Nielsen (2012). People that participated in the workshops were all from Chametla representing diverse backgrounds, among them housewives, students, politicians, entrepreneurs and government employees. From the confidence map all workshops participants stated that they know very well Chametla. This was confirmed since all were able to very rapidly locate their own houses. After this exercise, people located the most vulnerable areas to floods (Figure 3 -orange-). In addition, they also identified those areas less vulnerable, but that get some kind of flood in case of the presence of a severe storm (black), at this moment participants indicated that this problem occurred in the past, but it was incremented after the main road construction. This happened since it was built a little bit higher than their surroundings, blocking the incoming runoff. Workshops attendees listed and located those measures that has been taken after the presence of storm and hurricanes, one was the area enabled for flood drainage, and the other was the streets raking to eliminate all the deposited material product of run off and flood. This activity is executed by the inhabitants themselves and by the local 
government. Finally, the participants enumerated proposed activities that need to be taken to reduce floods affectations. Because the streets of Chametla are of dirt, people marked those that need to be paved to allow the pass of public transportation (indicated in dark blue with a bus icon). This measure could help people to get out of the flooded areas, as they reported than sometimes this situation could last several weeks, keeping they trapped in their houses. Another measure suggested was the construction of drainage tubes under the main road to allow water to flow to the sea (light blue).

To conclude with the workshop people was asked how they thought this map could be used and with whom. They said that firstly they can use the map to internally organize the community to do activities that reduce their vulnerability and secondly it can be utilized to ask for support to the authorities to do the proposed activities.

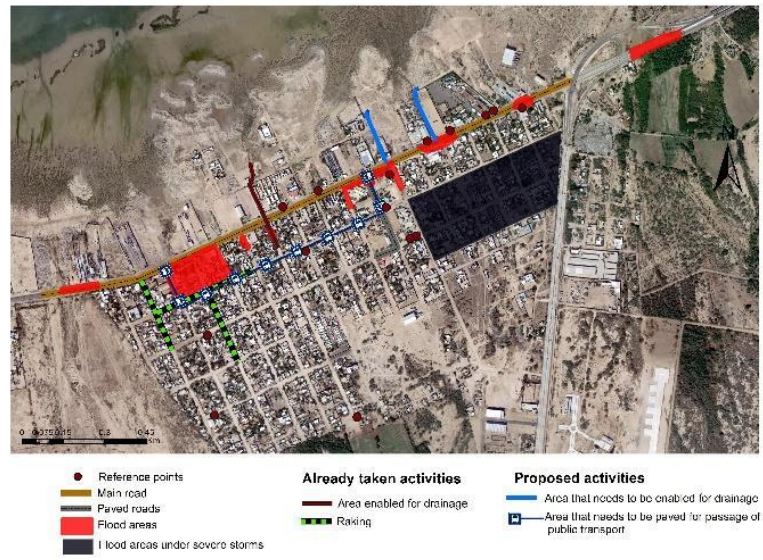

Figure 3. Community map. Household Survey. (Google Earth $\subset$, Image $(2017$ Digital Globe).

Comparison of the three levels of affectation of the houses (no affected, sporadically affected and regularly affected by floods) with socio economic factors showed no significant relationships (Table1 1).

\begin{tabular}{|c|c|c|c|}
\hline $\begin{array}{c}\text { Socioeconomic variable/ } \\
\text { Question }\end{array}$ & Test & $\begin{array}{l}\text { Statistic } \\
\text { value }\end{array}$ & $\begin{array}{c}P \\
\text { value }\end{array}$ \\
\hline Study levels & \multirow{2}{*}{ Gamma } & -.022 & .780 \\
\hline Socioeconomic Index & & .07 & .47 \\
\hline $\begin{array}{l}\text { If there is a hurricane } \\
\text { warning do you use some } \\
\text { kind of measurements to } \\
\text { prevent affectation in your } \\
\text { house? }\end{array}$ & \multirow[t]{4}{*}{$\begin{array}{l}\text { Chi- } \\
\text { squared }\end{array}$} & 2.57 & .276 \\
\hline $\begin{array}{l}\text { Had you make modifications } \\
\text { to your house to reduce flood } \\
\text { impacts? }\end{array}$ & & 3.61 & .164 \\
\hline $\begin{array}{l}\text { After and hurricane do you } \\
\text { ask for help to the local } \\
\text { government? }\end{array}$ & & .31 & .858 \\
\hline $\begin{array}{l}\text { Do you feel prepared for } \\
\text { storm or hurricane? }\end{array}$ & & 1.76 & .416 \\
\hline
\end{tabular}

Table 1. Value of the statistics (Gamma and Chi-squared) and significance ( $P$ value) for the relationship test between levels of affectation of the houses and socio economic factors.

Despite no relationship between the level of affectation and individual variables (study level), the socioeconomic index or the questions that show community preparedness against flood risk, we found that $93 \%$ of the people take some kind of measurements in case of a hurricane warning, this can be explained since the $45 \%$ of the people in Chametla has more than 9.1 years of education, which is the average for the country, besides $53 \%$ of the community fell in the high socioeconomic level of our index, which makes them less vulnerable. This asseveration can be reinforced since $90.6 \%$ do not ask for help to the local government and $64 \%$ of the people feel prepared for storm and hurricane.

\section{DISCUSSION}

Even though this was only a partial PGIS (since no people were trained in the use of the geographical information system technologies), giving back the mapping results to the community, was an important activity of this research, as it can drive change in the community converting the generated map in a tool for communication and negotiation. In this regard we agree with Canevari-Luzardo et al. (2017) in that PGIS is a helpful participatory tool to elicit and represent spatial knowledge about flood risk in order to make an informed deliberation for the definition and prioritization of the measures to be taken to manage risk and reduce vulnerability through an empowerment process. Results can help the community to become organized and prepared to take action and reduce risk and flood impacts. In addition the information generated in the mapping process can be used as citizen input by the decision makers (Forrester et al, 2003). In this case, having the mapping result commented by the disaster protection experts allowed to have an agreed tool that may be help to close the gap between citizens and government. It is of outmost importance in places, like the one in this study, where people do not interact with local governments to be prepared for and recover from flood affectations produced by hurricanes and severe storms. Besides, as stated by Spanu et al. 2015, participatory methodologies, like this partial PGIS, are a complement to the information provided by the experts to evaluate risk situations and support local governments in the decision-making process.

Implementing the partial PGIS approach based on the concepts of risk management and vulnerability reduction allowed to think on these problems as complex social processes in order to reduce risk levels in the community. The resulting map could help in the construction of new opportunities for the creation of more secure and sustainable settlements. These conditions could be guaranteed by the residents themselves based on a cooperative decision-making process. Review of the community map by experts showed that community suggestions are viable, demonstrating the value of local knowledge. An important factor was the acknowledgment by the workshop participants of their spatial knowledge. That is way we were especially interested not only in the products achieved from the activity, but in the mapping process itself. This highlights the importance of inclusionary approaches to knowledge co-production.

The generative tools were particularly useful to lead the participants to spatially identify reference familiar places that allow them locate their houses in the satellite image and then locate those places affected by floods (regularly and periodically), the evacuation routes, the measures already taken to face flood affectations and those proposed to manage risk and reduce their vulnerability. Of a particular importance in this study was the generation of a confidence map to evaluate the level of knowledge and trust on what was identified in the map. In this particular case, since Chametla is a relatively small area people 
reorganized and stated they know very well all the area and its problems.

\section{CONCLUSIONS}

The use of this methodology proved to be very simple and practical. Employing printed satellite images and generative tools seemed to work very well, avoiding the distrust that computing technologies could impose on the participants.

This study is innovative since it combined the information gathered in the participatory workshop with data collected in the survey. It was particularly helpful to understand how the affected houses relate to educational and socioeconomic conditions. In this case the community resulted to be relatively homogenous, may be because of their size and age, showing no statistical relationships between socioeconomic data and levels of household's affectations.

Finally, we can conclude that this activity could be easily replicated in bigger areas as a support for local planning in risk management and vulnerability reduction.

\section{ACKNOWLEDGEMENTS (OPTIONAL)}

This research was financed by the grant SEMARNAT-2015-01263102 (CNACYT/SEMARNAT), for the project entitled "Análisis de la Vulnerabilidad y Resiliencia al Cambio Climático en Sistemas Socio-ecológicos Periurbanos. We are extremely appreciative of the time and consideration given to us by the residents of Chametla. Many thanks to Antonina, Yuma and the staff of Civil Protection by their comments on the community map.

\section{REFERENCES}

Alfie, M., 2011. Comprometidos para Negociar. Conflicto y Gobernanza Ambiental (Holanda, Canadá y México). UAM Juan Pablos Editores, México.

Alfie, M., 2015. Conflictos socio-ambientales: la minería en Wirikuta y Cananea. El Cotidiano 191, pp. 97-108.

Allen, A., 2003. Environmental Planning and Management of the Peri-Urban Interface: Perspectives on an Emerging Field. Environment and Urbanization, 15(1), pp. 135-148. doi:10.1177/095624780301500103.

Aragón-Durand, F., 2007. Urbanization and Flood Vulnerability in the Peri-Urban Interface of Mexico City. Disasters, 31(4), pp. 477-44. doi:10.1111/j.1467-7717.2007.01020.x.

Ares, P., and Risier, J., 2016. Iconoclasistas Manual of Collective Mapping. CRitical Cartographic Resources for Territorial Processes of Collaborative Creation, Argentina.

Ayuntamiento de La Paz, BCS, 2017. Programa de Desarrollo Urbano de Centro de Población de La Paz, Baja California Sur. Plano 16 Crecimiento Urbano. Ayuntamiento de La Paz, BCS. Instituto Municipal de Planeación de La Paz, BCS.

Brown, G., and Fagerholm, 2015. Empirical PPGIS/PGIS mapping of ecosystem services: A review and evaluation. Ecosystem Services 13, pp. 119-133.

Brown, G., 2012. Public Participation GIS (PPGIS) for regional and environmental planning: reflections on a decade of empirical research. Journal of Urban Regional Information Systems Association 25(2), pp. 7-18.

Cadag, J.R.D., Gaillard, J.C. 2012. Integrating knowledge and actions in disaster risk reduction: the contribution of participatory mapping. Area, 44, pp. 100-109. 10.1111/j.14754762.2011.01065.x

Canevari-Luzardo, L., Bastide, J., Choutet, I., and Liverman, D., 2017. Using partial participatory GIS in vulnerability and disaster risk reduction in Grenada. Climate and Development, 9(2), pp. 95-109. https://doi.org/10.1080/17565529.2015.1067593.

Common Ground Project, 2008. Common Ground Community Mapping Project, www.commongroundproject.ca/projects. (31 January 2018).

Delgadillo, J., 1996. Desastres naturales. Aspectos sociales para su prevención y tratamiento en México. Instituto de Investigaciones Económicas, UNAM, México.

Forrester, J.M., Potts, L., Rosen, P., and Cinderby, J., 2003. Public involvement, environment and health: Evaluating GIS for participation. Do Geographic Information Systems for Participation (GIS-P) help to incorporate citizen inputs into science-based decision making? http://www.eldis.org/go/home\&id=14442\&type=Document\#.V bf5dOu5fzI (12 February 2018).

Green Map System, 2007. Think Global, Map Local! www.greenmap.org/greenhouse/en/about (8 February 2018).

Hernández, J., and Vieyra, A., 2010. Riesgo por inundaciones en asentamientos precarios del periurbano. Morelia, Una Ciudad Media Mexicana: ¿El desastre nace o se hace? Revista de Geografia Norte Grande, 47 (Dec.), pp. 45-62.

Hewitt, K. (ed.), 1983. The idea of Calamity in a Technocratic Age. Interpretations of Calamity. Allen and Unwin, London.

INEGI. 2012. XIII Censo de Población y Vivienda 2010. $\mathrm{http} / / / \mathrm{www} 3$.inegi.org.mx/sistemas/microdatos/Encuestas.aspx? c=34553 (27 November 2017)

Jiménez, M., Baeza, C., Matías, L.G, and Eslava, H., 2012. Mapas de índices de Riesgo a Escala Municipal por Fenómenos Hidrometeorológicos. Centro Nacional de Prevención de Desastres (CENAPRED)- Secretaría de Gobernación (SEGOB). México.

Lavell, A., 2004. Sobre la gestión del riesgo: Apuntes hacia una definición, http://www. bvsde.paho.org/bvsacd/cd29/riesgoapuntes.pdf (24 January 2018).

Luscombe, W., and Reyes, C., 2004. Building consensus in environmental decisionmaking - A methodology integrating GIS tools and structured communication. Paper presented at National Association of Environmental Professionals, USA.

Martin, B., and Hanington, B.M., 2012. Universal methods of design: 100 ways to research complex problems, develop innovative ideas, and design effective solutions. MA: Rockport Publishers, Beverly, pp. 213-214.

Martínez-Verduzco, G.C., Galeana-Pizaña, J.M, Cruz-Bello, G.M., 2012. Coupling Community Mapping and supervised 
classification to discriminate Shade coffee from Natural vegetation. Applied Geography 34, pp. 1-9.

Nielsen, J., 2012. How many test users in a usability study. In: Nielsen Norman Gr. https://www.nngroup.com/articles/howmany-test-users/ (24 January 2018).

Oštir K., Kokalj, Z., Saligny, L., Tolle, F., and Nuninger, L., 2007. Confidence maps: a tool to evaluate archaeological data's relevance in Spatial analysis. Proceedings of the 35th International Conference on Computer Applications and Quantitative Methods in Archaeology (CAA). Berlin, Germany

Registro Agrario Nacional, 2018. PHINA. Patrón e historial de núcleos agrarios. Ficha del núcleo agrario. phina.ran.gob.mx. (8 February 2018).

Sanders, E., Brandt, E., and Binder, T., 2010. A Framework of Organizing the Tools and Techniques of Participatory Design. Participatory Design Conference (PDC) Proceedings, 2010.

Sanders, E., and Stappers, P.J., 2012. Convivial design toolbox: generative research for the front end of design. BIS, Amsterdam.

Spanu, V., Gaprindashvili, G. McCall, M.K., 2015. Participatory Methods in the Georgian Caucasus: Understanding vulnerability and response to debrisflow hazards. International Journal of Geosciences, 6, pp. 666-674.

UNDP, 2004. La reducción de riesgos de desastres. Un Desafío para el Desarrollo. United Nations Development Programme (UNDP), New York.

Weijiang, L., Jiahong, W., Yanjuan, W., 2014. PGIS-based probabilistic community flood disaster risk assessment: A case of Taining County Town, Fujian Province. Geographical Research

Wilches-Chaux, G. 1998. La vulnerabilidad global in Maskrey, A. (ed.) Los desastres no son naturales. La Red, Bogotá, Colombia, pp.11-44.

Williamson, D., 2011. theirwork: the development of sustainable mapping. In Rethinking Maps: New Frontiers in Cartographic Theory. Routledge, New York, pp. 97-112.

Wisner, B., Blaikie, P., Cannon, T., and Davis, I. 2004. At Risk. Natural Hazards People's Vulnerability and Disaster. Routledge $\&$ Taylor and Francis Group, New York.

Zolkafli, A., Liu, Y., Brown, G., 2017. Bridging the knowledge divide between public and experts using PGIS for land use planning in Malaysia. Applied Geography 83, pp. 107-117. 